\title{
Acercamiento a las mediaciones en la producción simbólica pública de Las Villas en la medianía del siglo $X^{*}$
}

\author{
Dariel Mena Méndez ${ }^{* *}$ \\ Enma Fernández Arner** \\ Yamilet Ferrán Fernández ${ }^{* * * *}$
}

Recibido: 2017-05-16 Enviado a pares: 2017-05-25

Aprobado por pares: 2017-07-18 Aceptado: 2017-07-25

DOI: 10.22395/angr.v16n31al

\begin{abstract}
Resumen
El examen desde una visión hermenéutica, sistémica y de reflexividad de la producción simbólica pública de la sociedad insular en Cuba, durante el período republicano, décadas del 40 y 50 del siglo XX, acusa la pertinencia de la historiografía de la comunicación como constructo interdisciplinar, capaz de activar las relaciones procesuales entre las dimensiones económicas, jurídicas, políticas y culturales que distinguieron el período, a sus actores, estructuras y soportes, así como las mediaciones macro y micro que inciden en las articulaciones entre el sistema social y el sistema de comunicación pública, a escala de cuanto acontece en sociedades locales y regionales. El contexto de la Constitución del 40, de carácter democrático-burgués, impacta con singularidad la esfera de los derechos civiles, la participación de sectores históricamente invisibilizados, así como el empoderamiento de sectores comerciales, con presencia española e inmigrante, y una vida pública distintiva y plural que tendió al reforzamiento de una visión endógena regionalista.
\end{abstract}

El presente artículo, que responde a un estudio doctoral en curso, procura en clave inter- y transdiciplinar, y desde el análisis lógico-histórico, diacrónico, otorgar énfasis a la investigación documental, bibliográfica, el criterio de expertos y el análisis de contenido cualitativo, para una construcción conceptual y categorial inédita en el campo de la historia de la comunicación en Cuba.

Palabras clave: producción simbólica pública; Las Villas, prácticas culturales; historiografía de la comunicación.

Proyecto de investigación auspiciado por la Facultad de Comunicación de la Universidad de La Habana, Cuba.

** Facultad de Ciencias Sociales de la Universidad de Cienfuegos, Cuba.dmena@ucf.edu.cu

*** Facultad de Comunicación de la Universidad de La Habana, Cuba. enmafa@fcom.uh.cu

**** Facultad de Comunicación de la Universidad de La Habana, Cuba. yferran@fcom.uh.cu 


\title{
Approach to mediations in the public symbolic production of Las Villas in the Mid-20th Century
}

\begin{abstract}
The examination from a hermeneutic, systemic, and reflective view of the public symbolic production of island society in Cuba, during the Republican period, 40 and 50 decades of the 20th century, accuses the relevance of the historiography of communication as an interdisciplinary construct, able to activate the procedural relations between the economic, legal, political, and cultural dimensions that distinguished the period, its actors, structures and supports, as well as the macro and micro mediations that affected the articulations between the social system and the communication public system, at the scale of what happens in local and regional societies. The context of the Constitution of 1940, of a bourgeois-democratic nature, only impacts the sphere of civil rights, the participation of historically invisible sectors, as well as the empowerment of commercial sectors, with a Spanish and immigrant presence, and a distinctive public and plural life that tended to reinforce an endogenous regionalist vision.This article, which responds to an ongoing PhD study, seeks inter- and transdisciplinary key, and from the logical-historical, diachronic analysis, to give emphasis to the documentary research, bibliography, the criterion of experts and the analysis of qualitative content, for an unprecedented conceptual and categorical construction in the field of the history of communication in Cuba.
\end{abstract}

Keywords: public symbolic production; Las Villas; cultural practices; historiography of communication.

\section{Aproximação às mediações na produção simbólica pública de Las Villas em meados do século XX}

\begin{abstract}
Resumo
A análise, sob uma visão hermenêutica, sistêmica e reflexiva, da produção pública da sociedade insular em Cuba, durante o período republicano, décadas de 40 e 50 do século XX, demonstra a pertinência da historiografia da comunicação como construto interdisciplinar, capaz de ativar as relações processuais entre as dimensões econômicas, jurídicas, políticas e culturais que distinguiram o período, seus atores, estruturas e suportes, bem como as mediações macro e micro que incidem nas articulações entre o sistema social e o sistema de comunicação pública, a escala de quanto acontece em sociedades locais e regionais. O contexto da Constituição de 1940, de caráter democrático-burguês, impacta com singularidade a esfera dos direitos civis, a participação de setores historicamente invisibilizados bem como o empoderamento de setores comerciais, com presença espanhola e imigrante, e uma vida pública diferente e plural, que tendeu ao reforço de uma visão endógena regionalista. Este artigo, que corresponde a um estudo doutoral em andamento, procura, em termos inter e transdisciplinar, e sob a análise lógico-histórica, diacrônica, outorgar ênfase à pesquisa documental, bibliográfica, ao critério de especialistas e à análise de conteúdo qualitativa, para uma construção conceitual e categorial inédita no campo da história da comunicação em Cuba.
\end{abstract}

Palavras-chave: historiografia da comunicação, Las Villas, práticas culturais, produção simbólica pública. 


\section{Introducción}

La historiografía de la comunicación, si bien no ha sido depositaria de un consensuado reconocimiento en diversas comunidades académicas, paulatinamente ha ganado en estatura y configuración, primero, porque el propio campo ha contribuido a gestar una mirada a fenómenos y objetos en su sentido dialéctico y diacrónico, y en segunda instancia, porque el camino teórico para arropar lo comunicativo, más allá de lo massmediático, también ha ganado en emergencia y complejidad.

En el caso cubano, conviene referirse a los aportes de las profesoras Hanny Amaya y Ayrén Velazco (2007) en el artículo "Enfoques más recientes en la investigación cubana en comunicación. Aproximaciones a la obra de Manuel Martín Serrano", donde analizan el comportamiento de los estudios históricos en comunicación en el país, influenciados por la apropiación de la Teoría Social de la Comunicación. Refieren que ante la influencia de una tradición empírica con un marcado carácter instrumentalista, "[...] La existencia de numerosos estudios de este corte, así como su continuidad y estabilidad, permiten considerar a esta área como una de las más fructíferas dentro de la producción científica en este campo" (Amaya \& Velazco, 2007, p. 97).

Desde el punto de vista teórico-metodológico se vislumbran puntos de convergencia entre historia y comunicación social como dos campos disciplinares, quedando claro que la historia de la comunicación puede definirse como sub-campo de investigación en los estudios de comunicación y reconociéndose la necesidad de pertinentes diálogos con la historiografía y con los estudios culturales propiamente.

En el propio campo de los estudios históricos en comunicación se observa cierta condición de marginalidad, dada por la preeminencia de marcos sociológicos y de análisis sincrónicos que aún otorgan privilegio a los medios. (Amaya, 2008). De ahí la ambigüedad de su estatuto disciplinar, unido a la "escasez de reflexiones de orden teórico-epistemológico orientadas hacia su fundamentación y delimitación como ámbito de estudios. La abundancia de estudios empíricos en esta área contrasta con la inexistencia de una sólida fundamentación epistemológica, o de un cuerpo teórico consolidado" (Amaya, 2008, p. 128).

Es inevitable la necesidad de una expansión de la historiografía de la comunicación, considerando que se trata de una línea que, si bien ha gozado de sostenida tradición en los estudios de comunicación social en el país, aún son perceptibles nichos en esta modalidad de producción científica. La exigua ocupación en los contextos regionales y locales, a las mediaciones que intervienen en estos fenómenos, unidas a la necesidad de continuar extendiéndose las pesquisas hacia otros fenómenos comunicativos, y no precisamente massmediáticos, así lo demuestra.

De realizarse un examen desde la perspectiva historicista a la producción cultural de territorios, del interior de la Isla (provincias, municipios y comunidades), puede observarse cómo tanto en la representación que ciertos eventos y prácticas alcanzan en los medios, 
como en las diferentes expresiones de la cultura popular, las tradiciones, las costumbres, las celebraciones públicas, los acontecimientos cívicos auspiciados por gremios y sociedades, las procesiones y demás prácticas culturales subyacen y se estructuran formas simbólicas mediadas, que dan cuenta de lo singular y lo identitario que tipifican a estos espacios en la conformación de la socialidad, si bien no puede desestimarse la impronta de lo nacional y global en la configuración de algunos de sus rasgos más sobresalientes.

En ello también radica la necesidad de una apertura de la producción científica en historia de la comunicación pública desde la multi y transdisciplinariedad. Pudieran introducirse nuevas perspectivas para el análisis de los medios, las prácticas, las instituciones y sistemas o subsistemas comunicativos desde un asiento diacrónico e interpretativo, otorgando jerarquía al lugar que ocupan las mediaciones en este sentido.

A escala internacional, a pesar de que se presentan aspectos epistemológicos de referencia, no es menos cierto que se alude, por lo general, a espacios más urbanizados y complejos, que distan de la realidad cubana y de su historia. No se trata de un contraste ni de una nueva perspectiva teórico-metodológica, sino de un diálogo oportuno con las postulaciones existentes, al tiempo que se pretende una redefinición de la perspectiva historiográfica de la comunicación pública, que se ajuste a las realidades socio-históricas de la Isla y a las formas y modos en que se han de investigar los ámbitos específicos, otorgando valía a las mediaciones de aquellos aconteceres que tributan a la producción simbólica pública regional-local. "En consecuencia sigue abierto el estudio sistemático de todas las cuestiones cruciales para comprender las diferentes relaciones de interdependencia que existen, entre el cambio social y la transformación de la comunicación pública" (Martín Serrano, 1986, p. 22).

Asimismo, en relación con su paradigma, Martín Serrano apunta que no existe un enfoque teórico que relacione metódicamente las observaciones sobre todas las prácticas de comunicación pública por igual, pues es necesario considerar "(...) las peculiaridades que diferencian a las sociedades donde se producen" (Martín Serrano, 1986, p. 14). De ahí la justificación y pertinencia de nuestro objeto de investigación. Para ello, sus autores se proponen' explicar el impacto de las mediaciones en la producción simbólica pública regional y local de Las Villas² en la medianía del siglo XX.

Antecede a este fin: La comunicación pública de carácter local en las décadas de 1940 y 1950 del siglo XX: Cumanayagua como caso de estudio, defendida como parte de la XIII edición de la Maestría en Ciencias de la Comunicación en la Facultad de Comunicación-Universidad de La Habana (2014). Tributaron también varias pesquisas realizadas desde la carrera de Comunicación Social de la Facultad de Ciencias Sociales-Universidad de Cienfuegos.

\footnotetext{
Cabe destacar que este artículo se deriva de la tesis doctoral en Ciencias de la Comunicación cuyo título es, Fundamentos teórico-metodológicos para el análisis hermenéutico de la producción simbólica pública en los ámbitos regionales y locales cubanos en la medianía del siglo XX, que se defenderá en la Facultad de Comunicación de la Universidad de La Habana (FCOM).

2 Las Villas, provincia de la región central de Cuba. A mediados del siglo XX estaba integrada por seis partidos judiciales: Sancti Spíritus, San Juan de los Remedios, Santa Clara, Sagua La Grande y Cienfuegos.
} 
Se justifica la selección de Las Villas como escenario de estudio, a partir de las realidades socio-económicas que tipificaron al contexto, por la cercanía con la capital, por la dinamización de buena parte de sus prácticas culturales de fuerte acento económico y en la estructura de empleo del territorio (agricultura, labores de cestería, artesanía) bajo la impronta de sucesivos flujos migratorios de origen canario, así como por constituir sus municipios importantes puntos de encuentro y convergencia entre Oriente y Occidente.

Es necesario sostener que para este tipo de investigación, con énfasis en lo simbólico y desde la perspectiva hermenéutica, deberán examinarse a la vez, las analogías entre el Sistema de Comunicación Pública (SC) y el Sistema Social (SS), lo que permite desvelar las evidentes interdependencias dadas por las actividades económicas fundamentales, la estructuración de la sociedad, los flujos migratorios, la cultura y otras mediaciones e influencias axiomáticas que intervienen en la producción social de la comunicación y a las cuales se hará referencia en el presente trabajo.

Fue prevista la periodización que concierne a las décadas de 1940 y 1950 de la pasada centuria, a propósito de las aperturas que en el plano político y social se lograron con la Constitución de 1940, cuyos cambios se reflejaron de modo particular en la antigua provincia de Las Villas y en varios de sus municipios y localidades.

Desde el punto de vista empírico, el estudio propuesto confiere importancia, toda vez que propicia categorías y dimensiones para el arrimo a los fenómenos comunicativos y culturales de tipo regional-local, no restringiéndolo a lo massmediático, sino habilitando esto como una plataforma de fuentes desde donde también acercarse a los fenómenos culturales y a la carga de mediaciones que estos poseen.

Asimismo, se pretende dar respuesta científica ante las insuficientes investigaciones comunicológicas que se han encargado del tema en estos entornos y potenciar, desde un enfoque comunicacional y cultural más abarcador, las miradas que hasta la fecha se han realizado desde la historiografía regional-local.

Con respecto a la utilidad metodológica, vale apuntar que el estudio constituye un punto de partida para futuras indagaciones sobre sistemas o subsistemas comunicativos en cualquier escenario regional o local del país desde la perspectiva diacrónica, interpretativa y crítica, de manera que se diagnostiquen particularidades distintas por territorios o comunidades. Recuérdese que los procesos de producción y reproducción simbólica se desarrollan en la diversidad espacial y temporal, aun cuando se divisen articulaciones estructurales, cual herencia de lo nacional.

\section{Metodología}

\subsection{Objetivos específicos}

- Definir las categorías analíticas, sistema de comunicación pública regional-local y producción simbólica pública, apoyados en los presupuestos epistemológicos ofrecidos por diversas disciplinas sociales. 
- Examinar el alcance de las mediaciones macro y microsociales, que con mayor acento incidieron sobre los fenómenos de comunicación pública al nivel regional-local de Las Villas durante las décadas de 1940 y 1950.

\subsection{Tipo de investigación, perspectiva y diseño}

Es una investigación histórica, y por su perspectiva se clasifica como cualitativa. Los acercamientos que se realizan desde la perspectiva cualitativa propician herramientas para la explicitación de las realidades subjetivas e intersubjetivas, como objetos fidedignos del conocimiento científico. Es de este modo que la significación de las acciones humanas pueden ser investigadas, como procesos de construcción socio-histórica y cultural.

Una lectura reposada y analítica de varios textos que pretenden explicar en términos metodológicos y epistémicos al estudio de caso nos llevó a la apropiación de la clasificación que sustentan varios investigadores latinoamericanos de filiación educativa, en su Guía para la elaboración de estudios de caso (s. / f., material digital)³, tendente a considerar el presente tema como de comprensión ideográfica, pensado y concebido como fin y como método, y susceptible de ser etiquetado como un caso simple de diseño incrustado, en tanto, se toma como objeto de estudio la totalidad sociocomunicativa de Las Villas, desde el análisis de dos o más unidades, a saber, el subsistema mediático, las instituciones y las prácticas culturales, en su condición de tipologías orgánicas, homogeneizadoras y totalizantes de una realidad determinada; máxime cuando ninguna de estas clasificaciones se hicieron pensando en designar procesos históricos en sí mismos multi-discursivos.

\subsection{Categorías de análisis, métodos, técnicas y procedimientos}

Categorías: sistema de comunicación pública regional-local y producción simbólica pública.

Fue seleccionado el método histórico-lógico, asistido por el analítico sintético y el inductivo deductivo, a partir de la descripción de los rasgos que tipificaron estructural y simbólicamente el sistema de comunicación pública de configuración regional-local en un período histórico concreto, marcado por procesos y cambios sociales que caracterizaron a las comunidades seleccionadas y al contemplarse como "[... un sistema internamente lógico, que incluye subsistemas que se encuentran interrelacionados" (Román, 2000, pp. 119-128).

Entre los rasgos de análisis causal más común del método histórico, se encuentra el aspecto diacrónico, que es "tributario por tanto del análisis causal a través del cual se investigan los fenómenos del cambio social [...] tiene por objeto explicar las transformaciones de las sociedades a través del tiempo" (Balcells, 2000, p. 50).

Fueron aplicadas técnicas como: revisión bibliográfica-documental y las entrevistas en profundidad. El tipo de muestreo para este tipo de técnicas es el intencional.

Se trata del texto concebido por un colectivo de autores integrado por Díaz de Salas Sergio Alfaro, Mendoza Martínez Víctor Manuell, Porras Morales Cecilia Margarita. Disponible en www.razonypalabra.org.mx Fecha de consulta: 17 de febrero de 2014 
Algunos artículos de investigación que guardan relación con este tipo de estudio en el ámbito internacional son: "Procesos comunicacionales, sociedad local y desarrollo", de Arturo Granados Mogrovejo (2003); "La producción simbólica del espacio urbano en Noblejas", de Mónica Cornejo Valle (2003) y "Cultura y producción simbólica en la comunidad valenciana. Un análisis sectorial e implicaciones territoriales", de Pau Rausell Köster y Salvador Carrasco Arroyo (2003).

\subsection{Población y muestra}

El universo o población lo constituye la producción simbólica pública de Las Villas en la medianía del siglo XX, provincia que para este entonces estaba integrada por seis partidos judiciales (o municipios): Sancti Spíritus, San Juan de los Remedios, Santa Clara, Sagua La Grande y Cienfuegos.

La muestra se centra en una selección intencional de prácticas culturales, espacios de socialización y medios (prensa periódica y radio) de Santa Clara, Remedios, Cienfuegos, Sagua La Grande, y Cumanayagua como espacio local de menor complejidad.

La selección muestral se sustenta en el criterio no probabilístico, el cual nos permite decidir qué medios, prácticas y espacios serán examinados, como se muestra en la tabla 1.

\subsection{Criterios de selección de la muestra}

- Los medios de comunicación pública a examinar (la prensa y la radio) han de ser parte de la producción infocomunicativa local, si bien circularon otros procedentes de la capital y de los centros urbanos más próximos.

- En el caso de la prensa: periódicos, revistas y boletines, incluyendo los volantes de la época que respondieron a los intereses de organizaciones, sectores sociales y gremios villareños, cabe apuntar que el privilegio otorgado al tratamiento de temas locales en sus páginas constituyó una agenda significativa y prioritaria, que permitió acercarnos desde una posición crítica a las realidades socio-históricas del contexto en la periodización que nos ocupa y poner en diálogo dichas informaciones con lo referido en otras fuentes (documentales y orales).

- Otros criterios de selección muestral (incluso para las emisoras radiales) fueron: la periodicidad de producción y circulación con más de un año, el alcance, reconocimiento social y los índices de audiencia.

- En relación con las prácticas culturales y con los espacios de socialización examinados, fueron de interés los de mayor influencia hispánica. Recuérdese que Las Villas fue el centro que mayor asentamiento español tuvo desde la colonia; si bien no deben obviarse los matices norteamericanos en múltiples aconteceres socioculturales de la época, por lo que se produjeron tendencias hibridas en las diferentes formas de producción simbólica. 
Tabla 1. Delimitación muestral

\begin{tabular}{|c|c|c|c|}
\hline $\begin{array}{l}\text { Municipio o } \\
\text { localidad }\end{array}$ & $\begin{array}{l}\text { Medios de comunicación pública } \\
\text { local (prensa local y radio) }\end{array}$ & Prácticas culturales & Espacios de socialización \\
\hline Santa Clara & $\begin{array}{l}\text { Periódicos: La Publicidad, } \\
\text { El Villaclareño } \\
\text { Revistas: Revista Islas } \\
\text { Emisora: Cadena Azul }\end{array}$ & $\begin{array}{l}\text { Tertulias pueblerinas } \\
\text { Banda municipal } \\
\text { Carnavales } \\
\text { Las Verbenas }\end{array}$ & $\begin{array}{l}\text { Plaza de Armas (o Plaza Mayor), } \\
\text { Sociedad El Ateneo, } \\
\text { Café El Recreo, Sociedad La Bella } \\
\text { Unión, El Teatro La Caridad y } \\
\text { Sociedad Liceo }\end{array}$ \\
\hline $\begin{array}{l}\text { San Juan de } \\
\text { los Remedios }\end{array}$ & $\begin{array}{l}\text { Periódicos: El Criterio } \\
\text { Popular y El Sinsonte }\end{array}$ & $\begin{array}{l}\text { Las Parrandas de Remedio } \\
\text { La procesión de Semana } \\
\text { Santa } \\
\text { Feria de las Flores de Mayo } \\
\text { Ferias de San Juan }\end{array}$ & $\begin{array}{l}\text { La Iglesia Parroquial Mayor de } \\
\text { San Juan Bautista }\end{array}$ \\
\hline $\begin{array}{l}\text { Sagua La } \\
\text { Grande }\end{array}$ & $\begin{array}{l}\text { Periódicos: Antorcha, La } \\
\text { Defensa, Mensaje y La Voz } \\
\text { de Sagua }\end{array}$ & & $\begin{array}{l}\text { Colonia China, Casino Chung } \\
\text { Wah, Sociedad Liceo, El Casino } \\
\text { Español }\end{array}$ \\
\hline Cienfuegos & $\begin{array}{l}\text { Periódicos: La Correspon- } \\
\text { dencia, El Comercio, Noti- } \\
\text { cias de Hoy, Prensa Libre, } \\
\text { Volantes: de la Asociación } \\
\text { de Comerciantes de la } \\
\text { calle Castillo } \\
\text { Revistas: Revista Atenea, } \\
\text { Revista Estudiantina, } \\
\text { Revisa Reporter, Revista } \\
\text { ACPC(AcciónConstructiva } \\
\text { Pro-Cienfuegos) y la } \\
\text { Revista Catalana } \\
\text { Radio: la CMHM, CMHX, } \\
\text { CMHJ y Radio Tiempo }\end{array}$ & $\begin{array}{l}\text { Carnavales } \\
\text { La Fiesta Patronal de la } \\
\text { Virgen de la Caridad del } \\
\text { Cobre } \\
\text { La festividad de Santa } \\
\text { Bárbara } \\
\text { Fiesta Patronal de San } \\
\text { José de la Montaña } \\
\text { La Fiesta Patronal de la } \\
\text { Purísima Concepción }\end{array}$ & $\begin{array}{l}\text { Espacios públicos: El Paseo del } \\
\text { Prado, La Plaza de Armas, El } \\
\text { Malecón de Cienfuegos, Parque } \\
\text { Enrique Villuendas, Glorietas, } \\
\text { Mercado Municipal, Parque } \\
\text { Aduana, Parque José Martí, } \\
\text { Parque Villuendas y los teatros } \\
\text { Tomás Terry y Luisa. } \\
\text { Sociedades y clubes: Sociedad } \\
\text { Liceo, Asociación Canaria de } \\
\text { Cienfuegos, Casino Español, Club } \\
\text { Asturiano, El Club de Leones, } \\
\text { Sociedad Unión Club, Colonia } \\
\text { China de Cienfuegos, Yacht Club } \\
\text { de Cienfuegos y la Sociedad } \\
\text { Minerva }\end{array}$ \\
\hline Cumanayagua & $\begin{array}{l}\text { Periódicos: El Defensor, } \\
\text { El Triunfo, Alma Guajira, } \\
\text { Aspas, La Tripa } \\
\text { Revistas: Urbe y Argos } \\
\text { Boletines: Rugidos y } \\
\text { Amistades } \\
\text { Volantes: A los vecinos de } \\
\text { Cumanayagua, Barajagua, } \\
\text { Ojo de Agua y Arimao; } \\
\text { Declaración de Principios, } \\
\text { Alocuciones al Pueblo y } \\
\text { Pueblo y Revolución. }\end{array}$ & $\begin{array}{l}\text { Procesión de La Santa } \\
\text { Cruz de Cumanayagua, } \\
\text { los festejos de San } \\
\text { Juan, la celebración de } \\
\text { Las Candelarias, los } \\
\text { Alumbrados, El Teatro } \\
\text { Sacro y la Banda Municipal } \\
\text { de Música }\end{array}$ & $\begin{array}{l}\text { Sociedades y clubes: El Casino } \\
\text { Español, El Club Progresista, La } \\
\text { Sociedad Liceo y el Casino Chung } \\
\text { Wah } \\
\text { Espacio público: El Prado }\end{array}$ \\
\hline $\begin{array}{l}\text { Sancti } \\
\text { Spíritus }\end{array}$ & Periódicos: El Fénix & Carnavales & $\begin{array}{l}\text { Sociedades espiritistas: Luz } \\
\text { Divina, Fidelidad del Alma y El } \\
\text { Ángel Tutelar } \\
\text { Iglesia Católica }\end{array}$ \\
\hline
\end{tabular}

Fuente: elaboración propia 
Las líneas que siguen privilegian algunas ideas definitorias en torno a las categorías analíticas y se reflexiona acerca de las mediaciones en la producción simbólica pública de Las Villas a mediados del siglo XX. La descripción de estas prácticas y medios de comunicación quedan como temas pendientes para otras publicaciones de los autores.

\section{Categorías de análisis: conceptualización}

\subsection{Sistema de comunicación pública regional-local}

La perspectiva subsistémica, también se ajusta y analiza desde las áreas que atañen a la comunicación pública en los ámbitos específicos, el subsistema mediático, por ejemplo, al tratarse de los medios enmarcados en municipios, comunidades o representativos de algún partido, gremio o asociación. García Luis (2004, p.13) establece que:

Bajo la determinación del sistema social prevaleciente, que abarca un determinado sistema político y jurídico, un contexto cultural y social, un régimen de propiedad y un ordenamiento profesional dado, en cada país se configura el correspondiente subsistema de medios de comunicación pública, el cual adopta en su organización, estructura, formas de gestión y funciones, los estilos y contenidos que resultan coherentes con el contexto en que actúan.

Por otro lado, los componentes (estructura, infraestructura y supraestructura), si bien, en el sistema social o en el comunicativo poseen características particulares y modos diferentes de producción, son ineludibles sus analogías a partir de las interdependencias sociohistóricas que afectan a ambos.

La pertinencia de estas áreas de estudio como parte de la comunicación, la sociedad y sus implicaciones en la construcción de lo público local puede entenderse de forma holística, ya que "[...] múltiples canales, espacios de participación y prácticas han de abrirse a la construcción de lo público" (Nápoles, 2007, p. 40).

En esencia, la comunicación pública y sus diferentes modalidades de producción simbólica no solo constituyen objetos de análisis en los centros urbanos de mayor complejidad, sino que la aproximación empírica a los ámbitos regionales y locales (los subsistemas de comunicación pública -o- sistemas de comunicación pública regional-local) han de confirmarse a partir de la intersección de mensajes que son compartidos horizontalmente a través de diferentes canales y dispositivos, tales como los medios comunitarios (prensa, radio, televisión y medios digitales), los espacios de socialización o públicos (plazas, prados, parques, avenidas, glorietas y mercados), instituciones de sociabilidad (gremios, asociaciones, clubes) y cualquier otro escenario de encuentro en el cual los sujetos sociales como miembros y actores de la comunidad, protagonizan actos, audiencias públicas, foros ciudadanos, reuniones de organizaciones populares y asambleas, donde comparten experiencias, ideas, opiniones, demandas y asisten a determinadas ceremonias o prácticas culturales. A estos medios, aconteceres y contextos los denominamos como fenómenos de comunicación pública regional-local. Barbero alude a la presencia y articulación de "[...] redes y flujos más que de encuentros" (Martín-Barbero, 2010, pp. 37-51). También plantea que de 
este modo "[... cada región, cada localidad, cada grupo reclama el derecho a su memoria" (Barbero-Barbero, 2001, p. 18). Es en este sentido que se requiere de un

[...] desplazamiento metodológico para rever el proceso entero de la comunicación desde su otro lado: el de las resistencias y las resignificaciones que se ejercen desde la actividad de apropiación desde los usos que los diferentes grupos sociales -clases, etnias, generaciones, sexos- hacen de los medios y los productos masivos (Martín-Barbero, 1989, pp. 21- 26).

En el estudio, Procesos comunicacionales, sociedad local y desarrollo. Esfera pública local, se reflexiona sobre "[...] el debate de las esferas públicas, la opinión pública y su relación con los sistemas democráticos y el desarrollo. El ámbito territorial que se propone para esta reflexión es el local" (Granados, 2003, p. 3).

Para comprender las singularidades que cualifican la comunicación pública en municipalidades, parroquias o ayuntamientos, debemos partir del criterio de Martín Serrano (1986), cuando deja por sentado que la comunicación debe asumirse en su sentido más amplio. No solamente se refiere al hecho de compartir información, sino también al quehacer individual y colectivo que engloba el producto de las transferencias e intercambios de ideas, hechos y datos.

Es decir, que la comunicación organizacional, como ocurre con la mediática, no agota lo simbólico que es tributado por la sociedad al espacio público en todas las interacciones e intercambios en los que concurren los sujetos sociales: en las calles, en las plazas, en los prados, en los mercados y en otros sistemas institucionales. Cuando Martín Serrano define a la comunicación pública como, "Forma social de la comunicación en la cual la información se produce y distribuye por el recurso a un Sistema de Comunicación especializado que concierne a la comunidad como un conjunto" (Martín-Serrano, 1986, p. 79) alude fundamentalmente a centros más urbanizados, complejos e institucionalizados.

Al tratarse de la comunicación pública regional-local, se manifiesta o expresa a expensas, más que en otros espacios urbanos, del crecimiento demográfico, del desarrollo de la economía, de la construcción de vías de comunicación, por la presencia de medios de transporte, por razón de la extensión territorial de la comunidad, por el asentamiento de inmigrantes y por las dinámicas en que se construye lo público. Es en este sentido que lo comunitario, lo popular y lo emergente toman un sentido con mucha más naturalidad, a diferencia de cómo ocurren estos procesos en las grandes ciudades. Es así como las prácticas de comunicación pública adquieren un rango totalmente novedoso e impactante, donde la interacción de los sujetos sociales, a pesar de darse en un nivel de menor envergadura, revelan una dependencia mayor de las mediaciones y de los cambios de la sociedad.

Estas prácticas coadyuvan y contribuyen a la construcción de lo público y a la formación de significados compartidos, así como a la existencia de canales de información por el recurso a la oralidad. La comunicación pública y popular en espacios urbanos especí- 
ficos no solo abarca lo mediático, sino que hay otros aconteceres que sin la mediación tecnológica tributan a lo público local.

Sin embargo, coincidiendo con Jesús Martín Barbero, es válido aclarar que no podemos pensar lo popular al margen de la construcción socio-histórica de lo masivo,

[...] es decir, del acceso de las masas a su visibilidad y presencia social. Lo que implica que no podemos seguir en una crítica que desliga la masificación de la cultura del hecho político que genera la emergencia histórica de las masas y del contradictorio movimiento que constituye a lo masivo en modo de existencia de lo popular (Martín-Barbero, 1989, pp. 21- 26).

Por tal motivo, asumir lo regional y lo local entraña nuevos modos de entender los procesos de comunicación pública a partir de posicionamientos diversos, donde los niveles de urbanismo y de socialidad no se solidifican en igualdad de condición en relación con otros espacios de mayor generalidad. De este modo, la comunicación pública regionallocal se sostiene en los procesos y prácticas socioculturales, a partir de los modos en que se produce, distribuye y consume la información y todo tipo de contenido simbólico.

\subsection{Producción simbólica pública}

Lo simbólico, como categoría conceptual de análisis en el escenario de la comunicología, ha ganado espacio al estar entre los términos privilegiados en el campo de aquellas ciencias sociales que le han conferido tributos a la construcción teórica de la comunicación. Baste mencionar los debates epistemológicos aportados por la antropología cultural, la sociología, la lingüística y la filosofía. Autores de estas áreas han abordado el tema de distintas formas. Blumer utiliza el concepto de interaccionismo simbólico, al considerar que "La comunicación es simbólica, ya que nos comunicamos por medio del lenguaje y otros símbolos; es más, al comunicarnos creamos o producimos símbolos significativos" (Blumer, 1969, p. 12).

Pierre Bourdieu, aporta el término de capital simbólico, el cual consiste en aquellas propiedades impalpables, inefables y cuasi-carismáticas que, a su vez, son inherentes a la naturaleza misma del ser humano, tales como la autoridad, la reputación, el prestigio, la popularidad, la notoriedad, la honestidad, el talento, el don, el gusto, la inteligencia, etc., "no es más que el capital económico o cultural en cuanto conocido y reconocido" (Bourdieu, 1987, pp. 13-19). En Thompson, se observa un marcado énfasis en dicha categoría, al referir que:

La concepción descriptiva de la cultura se refiere al conjunto diverso de valores, creencias, costumbres, convenciones, hábitos y prácticas característicos de una sociedad particular o de un periodo histórico. La concepción simbólica desplaza el enfoque hacia un interés por el simbolismo: de acuerdo con ella, los fenómenos culturales son simbólicos, y el estudio de la cultura se interesa esencialmente por la interpretación de los símbolos y de la acción simbólica (Thompson, 1993, p. 184). 
El componente público en dicho concepto, aunque poco especificado, no ha dejado de estar presente, y es que todo fenómeno y práctica cultural entra en contacto con la esfera de lo público, toda vez que exista producción, transmisión, reproducción y consumo de informaciones contenidas en los medios, las ceremonias, los rituales, los cultos y en las celebraciones en las cuales los sujetos sociales se relacionan por el recurso a la oralidad y por otras vías y canales de comunicación. En el escenario de la comunicación de masas, se observa que cada una de las formas simbólicas son producidas y transmitidas cotidianamente mediante el uso de la tecnología.

Por tanto, la producción simbólica pública es la representación de las prácticas sociales en las cuales las informaciones circulan por distintas vías y canales, dejando una impronta y o significación en la sociedad. Ocupan un lugar de referencia los espacios de socialización, en los cuales se originan y se comparten todo tipo de contenido mediante signos y símbolos, capaces de construir sentidos e imaginarios colectivos que trascienden a la cultura y la identidad de un contexto en un periodo socio-histórico concreto.

Los festejos populares, los carnavales, las procesiones y las ceremonias religiosas, los eventos gremiales, los bailes, el teatro, las parrandas, las charangas, las comparsas, y hasta las manifestaciones civiles figuran en este caleidoscopio de prácticas y significaciones.

Nos encontramos frente a un proceso de evolución profunda de las sociedades contemporáneas, donde la esfera del trabajo, el papel del conocimiento, la expansión de las industrias culturales y la producción massmediática se constituyen como un sistema complejo que conlleva a desplazamientos clave en cuanto a la función de estas en las prácticas de producción simbólica, de la información y del saber (Brea, 2009).

Las prácticas de producción simbólica son las detonantes más evidentes que intervienen en la reproducción de la comunidad, al poseer la capacidad de subjetivación y socialización: "las prácticas culturales son las principales detentadoras del encargo social de producir comunidad y vida propia, de alimentar los procesos de subjetivación y socialización, y es en ello donde reposa y se articula todo el potencial de su creciente valor simbólico" (Brea, 2009, p. 13).

A nuestro breve intento de conceptualización, conviene ultimar con el criterio de que en los contextos regionales, y específicamente en los ámbitos de configuración local, la comunicación pública y la producción simbólica pública han de ser entendidas como dos categorías analíticas que poseen profundos puntos de convergencia, al compartir en común otras subcategorías, tales como cultura popular, prácticas culturales y comunicativas, producción massmediática local, espacios de socialización (espacios públicos y organizaciones comunitarias, clubes, gremios y sociedades), identidad y autoctonía.

En conclusión, se entienden por comunicación pública de configuración regional y local las prácticas y aconteceres en los cuales circula todo tipo de información y contenido simbólico, y cuyos protagonistas son los sujetos sociales que radican en un entorno de menor generalidad. La producción simbólica pública es la significación y alcance social de estos fenómenos. 
La incidencia de los aspectos estructurales, infraestructurales y supra-estructurales constituye directrices metodológicas que permiten analizar la producción simbólica pública regional / local desde un asiento dialéctico-hermenéutico. Se trata de un discurso en el cual son evidentes las relaciones de interdependencia entre el Sistema de Comunicación Pública y el Sistema Social.

\subsection{Mediaciones en la producción simbólica pública}

Lo referido anteriormente permite entender cómo los sujetos sociales construyen sus propias dimensiones de lo público a través de diferentes vías y canales. Nótese aquí la presencia de mediaciones, vitales para entender lo específico de la comunicación en estos ámbitos. La ubicación geográfica, los flujos migratorios (el asentamiento de inmigrantes), la estructura económica (del comercio y de negocios locales), la construcción de vías de comunicación, la demografía, el crecimiento poblacional, la incidencia de la enseñanza pública, las coyunturas políticas, la cultura popular y la religiosidad, unidas a los diálogos entre la trilogía nacional-regional-local, propician este tipo de pesquisa, insertada en la línea de investigación de historiografía de la comunicación.

La producción historiográfica de la comunicación ha de sustentarse en la comprensión dialéctico-interpretativa de los fenómenos que tienen lugar en diferentes espacios y periodizaciones. No basta con la aportación de datos cronológicos u otros elementos que se describen en el proceso empírico. Para arribar a discursos responsables y fidedignos es imprescindible acudir a herramientas propicias de interpretación, máxime cuando se trata de ámbitos locales de los cuales muy poco se ha escrito al respecto.

Es necesario entender que cada uno de los fenómenos comunicativos y culturales que se dan en estos espacios son producciones simbólicas que tienen diferentes formas de expresión, en correspondencia con las mediaciones y las características típicas de cada comunidad. La producción de signos y símbolos, sea cual fuere el recurso utilizado al efecto, es un proceso inevitable para el establecimiento de las relaciones históricas y cotidianas de los sujetos sociales. Examinar las relaciones de interdependencia entre el sistema social y el sistema comunicativo nos obliga a examinar los aspectos estructurales, infraestructurales y supra-estructurales.

Estructura: son las organizaciones mediadoras (redes, instituciones, industrias para la producción comunicativa, agencias de información, medios (...).

Infraestructura: circunstancias técnico-organizativas, recursos materiales y tecnologías.

Supraestructura: posturas e inclinaciones políticas, afiliación ideológica y creencias religiosas.

La coyuntura nacional y sus diálogos con la comunicación pública regional y local es un proceso configurativo en el cual se remedan todo tipo de influencias en múltiples direcciones. Las mediaciones relacionadas con los procesos migratorios y las referentes a la enmarcación geográfica son ejemplos a considerar. En el caso de la antigua pro- 


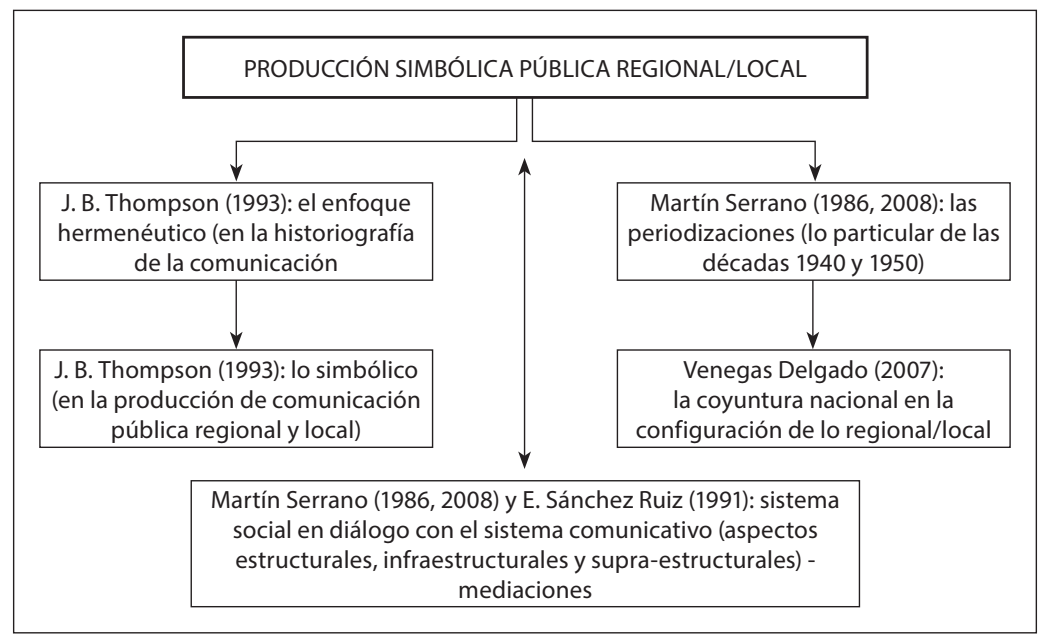

Esquema 1. Dimensiones teórico-metodológicas para el examen de las mediaciones en la producción simbólica pública regional-local

Fuente: elaboración propia

vincia de Las Villas, recuérdese que por el hecho de encontrarse cercana a la capital, y por poseer una ubicación geográfica, que además, propiciaba todo tipo de influencias tanto del Oriente como del Occidente de la Isla, dio lugar a la circulación de prácticas, ideologías, dogmas y tendencias que se asentaron en los municipios y en muchas de sus localidades.

De realizarse un retroceso en el tiempo, podremos percatarnos de que la presencia de patrones típicos de centros urbanos en sociedades capitalistas tuvo su expresión en ciudades como Cienfuegos, Santa Clara, Sagua La Grande, San Juan de los Remedios y Sancti Spíritus. Las prácticas sociales de la época, a saber: acontecimientos socioculturales, gremiales, políticos, religiosos y económicos, si bien en todos los contextos tuvieron formas distintas de expresión, asimismo, se observan matices que las hacín parte de una cultura dominante, muy marcada por la presencia de hispanos desde siglos pasados, unido a lo que se diseminaba en términos simbólico-culturales e ideológicos a propósito de la presencia norteamericana en disímiles campos de la vida social.

En el caso de Cuba, la historiografía de la comunicación, tanto a nivel nacional como regional o local, pudiera examinarse a partir de las periodizaciones establecidas por las ciencias históricas para el estudio de sucesos de otra índole; pero no precisamente se deben establecer segmentaciones temporales rígidas, considerándose que la comunicación pública no tuvo, ni tiene, igual grado de desarrollo, ni está atada a los acontecimientos y hechos históricos que tradicionalmente han sido examinados por los historiadores. Ello también depende de los intereses del investigador; si la idea es examinar el papel de la prensa en ámbitos estudiantiles y gremiales, son los años veinte y treinta los de mayor riqueza, unido al movimiento revolucionario de entonces. 
En el caso particular de las décadas de 1940 y 1950, el valor agregado se debe a las aperturas otorgadas por la Constitución de 1940, que si bien no se trata de un estatuto que haya otorgado cambios sustanciales al nivel macro-social, fue muy evidente el auge y expansión de un movimiento moderno que tuvo especial repercusión en Las Villas.

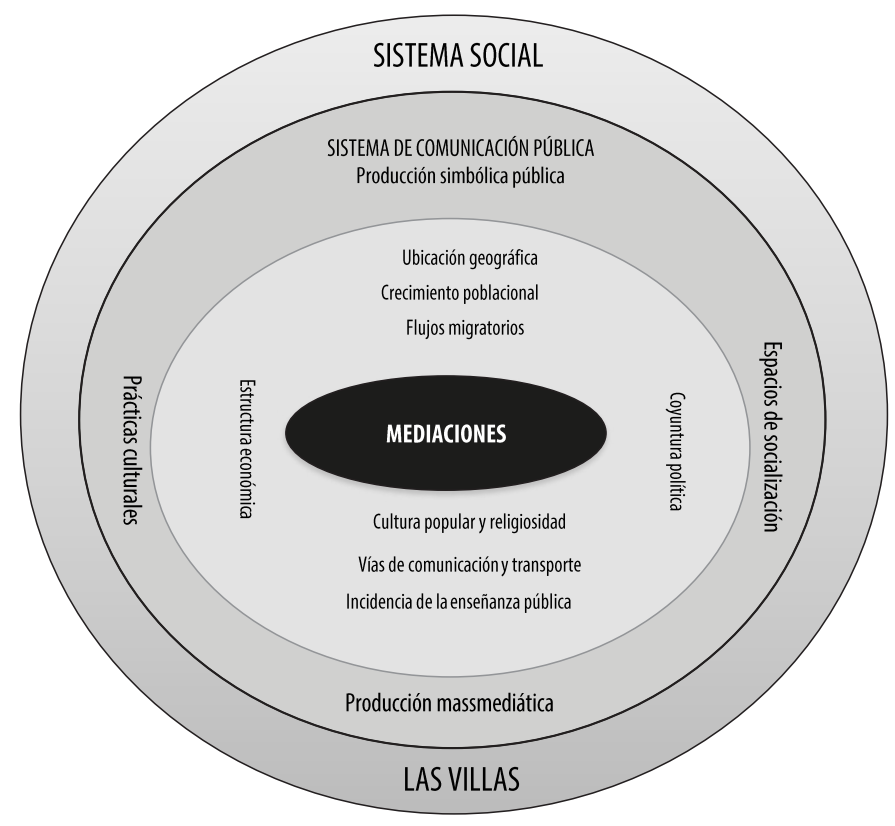

Esquema 2. Mediaciones en la producción simbólica pública regional-local de Las Villas en la periodización (1940 y 1950)

Fuente: elaboración propia

\subsubsection{La ubicación geográfica}

Como ya fue dicho por los autores, es un aspecto que exige diferentes interpretaciones; primero, por la cercanía de Las Villas con la capital (La Habana), favoreciendo influencias económicas, socioculturales e ideológicas; segundo, por enmarcarse en el centro de la Isla, convirtiéndose en punto también de encuentro entre el Oriente y el Occidente y, tercero, por las diversas posibilidades que brindó esta enmarcación hacia el interior de la propia provincia, tanto en términos económicos, como por la circulación de patrones socioculturales:

Cienfuegos, al ser una ciudad portuaria; Santa Clara por estar en el centro mismo de la región, teniendo contactos más directos con el resto de los ayuntamientos y localidades y Sancti Spíritus y Trinidad, por poseer la mayor parte de áreas montañosas, con tierras fértiles para la producción cafetalera. 
Cabe destacar la cercanía entre Cumanayagua, perteneciente a Cienfuegos y Manicaragua, a Santa Clara, lo que dio lugar a relaciones comerciales, políticas y sociales entre ámbitos locales muy similares por estos años.

\subsubsection{Los flujos migratorios}

La presencia de canarios, asturianos, catalanes, gallegos y chinos desde la etapa colonial en Las Villas fue evidente. Desde siglos pasados, notables influencias tuvo este fenómeno en el espectro económico y sociocultural. Recuérdese que la producción simbólica, prácticas comunicativas y culturales, espacios de socialización, producciones massmediáticas (la prensa) y demás procesos que se inscribieron en el sistema comunicativo fueron reflejo de tales representaciones.

Datos aportados por la historiografía demuestran que, si bien este fenómeno tuvo mayor auge en los siglos XVIII y XIX, luego de 1902 se perciben ciertos reacomodos y reorganizaciones del sector foráneo que se había aplatanado en Cuba, al tratarse de un cambio del sistema social precedente por un nuevo modelo de dominación neocolonial.

Puede aseverarse que este reajuste se relaciona con las actividades económicas asumidas y la consolidación de las tendencias asociacionistas y de sociabilidad. La consolidación de los gremios, clubes, sociedades y demás sistemas institucionales, unida a las prácticas culturales y al quehacer de la prensa periódica, otorgó al sistema de comunicación pública regional-local un matiz diverso para la representación de intereses, ideologías y credos, que si bien estuvieron influenciados por las nuevas tendencias de la Modernidad, no se desentendieron de las esencias socioculturales típicas de su contexto.

En el caso particular de Cienfuegos, el mayor asentamiento fue de catalanes y asturianos, con incidencia particular en el desarrollo del comercio. Ello hizo que el municipio llegara a convertirse en la ciudad comercial más importante de Cuba.

Sagua La Grande se bautizó como el centro de mayor asentamiento de chinos, dedicados en su colectividad a la agricultura en la periferia urbana y concurrían directamente al mercado con sus productos. Fue el Casino Chung Wah de este municipio el de más actividad en la región central, lo que dio lugar a influencias que fueron adoptadas por otras localidades del interior de Las Villas donde se habían establecido asiáticos procedentes de China.

En San Juan de los Remedios y Santi Spíritus predominaban los canarios, dedicados al cultivo del tabaco. Santa Clara, más cosmopolita en su condición de capital de la provincia central, se caracterizó por la diversidad de inmigrantes, tanto europeos como asiáticos. "Se dedicaron en su mayoría a la producción tabacalera, también se hacían presentes en el servicio doméstico, el comercio minorista y otros pequeños negocios, así como en las tareas de ampliación y reparación de ferrocarriles" (Farrill, D; Yedra, B E Venegas, 2010, pp. 145-242). 


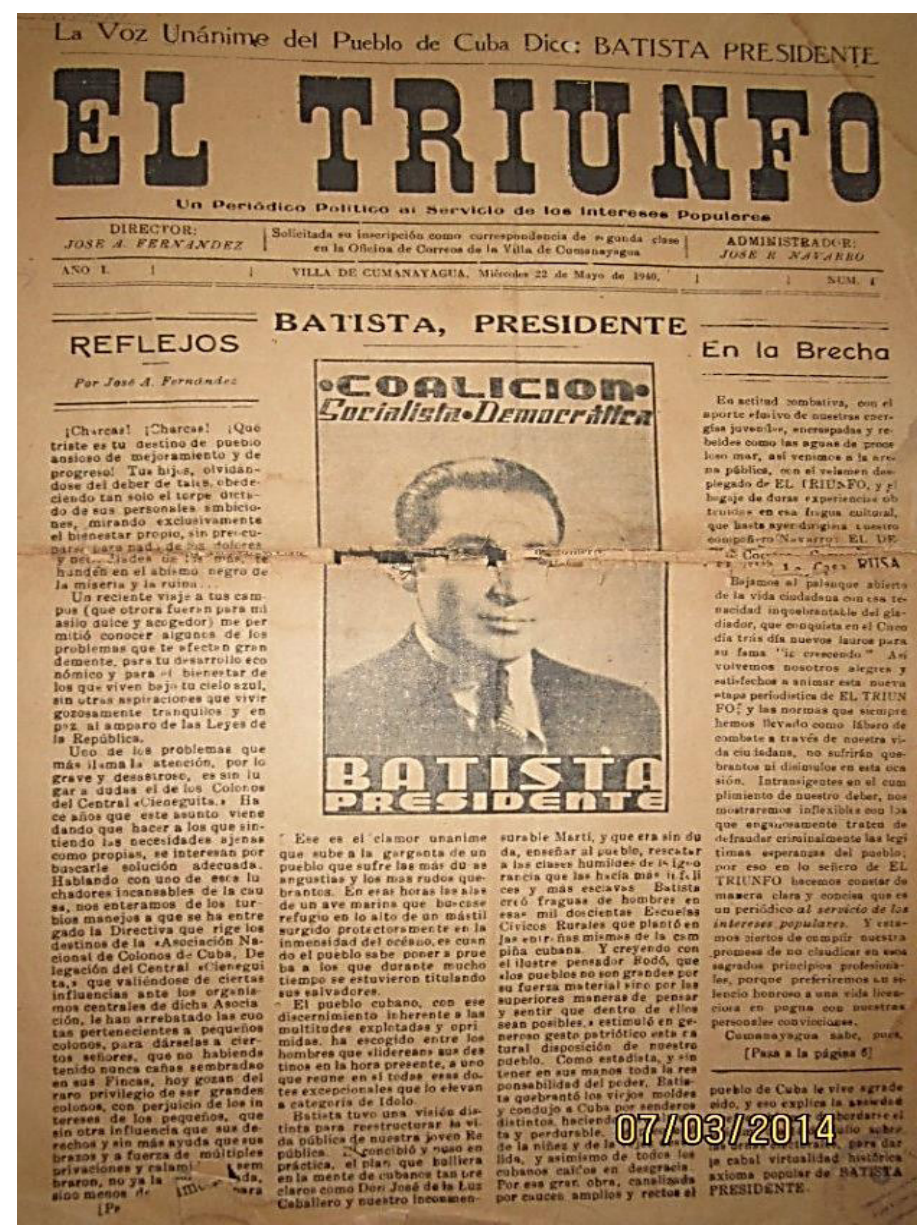

Imagen 1. Periódico local de Cumanayagua El Triunfo (1940) Fuente: Mena, Méndez, Dariel. 2014.

Se añaden los flujos migratorios internos, dados por la circulación y establecimiento de comerciantes y familias en los municipios y localidades de Las Villas; por lo general, de procedencia oriental, siendo Cienfuegos y Santa Clara los destinos más comunes.

El éxodo hacia La Habana fue un factor que favoreció el contacto directo entre las familias establecidas en la capital con los parientes que permanecieron en los municipios y localidades del centro. De igual manera, estos procesos se vieron reflejados en las prácticas culturales y en las relaciones de comercio.

$4 \quad$ Fuente: Mena, Méndez, Dariel. 2014. La comunicación pública de carácter local en las décadas de 1940 y 1950. Cumanayagua como caso de estudio. Tesis de maestría en Ciencias de la Comunicación. Facultad de ComunicaciónUniversidad de La Habana. 
Recuérdese también, que la migración externa se debió al éxodo hacia Estados Unidos. Influyeron en este aspecto, las relaciones socioeconómicas a propósito de la existencia de consulados norteamericanos en Las Villas, como el establecido en Sagua La Grande.

\subsubsection{Estructura económica}

Tanto la migración, como el alcance de la estructura económica, con acento en el comercio industrial y minorista, el desarrollo agrario (ganadería, producción cafetalera, tabacalera y la plantación de caña de azúcar), la prestación de bienes y servicios, la confección textil y la actividad portuaria son dimensiones que en el caso particular de Las Villas estuvieron profundamente relacionadas, dando cuenta de una economía local diversa y en crecimiento.

Las relaciones entre la actividad económica y el desarrollo de la comunicación pública, permite entender cómo los diferentes gremios campesinos y obreros contaban con sus propios periódicos, boletines o revistas, financiados con la recaudación de sus utilidades, unido también a los reportes de la actividad publicitaria, en crecimiento por estos años. Asimismo, se derivó de la economía local el financiamiento para la construcción de obras públicas, tales como parques, paseos, glorietas, avenidas, plazas y edificaciones. Notables influencias tuvieron en estas actividades las iniciativas de los gremios y asociaciones de la provincia y sus localidades.

Según consta en el censo de 1952, la ganadería, como otra actividad económica de la época, tuvo como territorios con mayor número de cabezas a Santa Clara, Vueltas, Santo Domingo, Remedios, San Diego del Valle, Esperanza y Placetas. Sagua La Grande se vio más favorecida por el desarrollo de la producción azucarera, con incidencia en el crecimiento poblacional y urbano.

\subsubsection{La construcción de vías de comunicación y el transporte}

Lo más relevante fue el acceso inmediato que tuvieron Santa Clara y Cienfuegos a la carretera central que comunicaba las diferentes regiones de Cuba. Si bien, desde años precedentes las vías terrestres del interior se encontraban en estado crítico, hacia las décadas de 1940 y 1950, se observan mejoras que favorecieron las conexiones entre municipios y localidades.

Debe agregarse la construcción de las líneas férreas y el impacto que tuvo particularmente en el espectro socioeconómico de Las Villas. Papel importante desempeñó la conexión ferroviaria entre Cienfuegos y Santa Clara, cuyas líneas atravesaban a la localidad de Cruces. Asimismo, el ferrocarril Sagua-Cienfuegos "permitió el embarque de la producción de la zona occidental de la región de Santa Clara por el puerto cienfueguero" (Farrill, Yedra E Venegas, 2010, pp. 145-242). La ampliación de la línea de Caibarién a Morón contribuyó con este movimiento.

A ello se añade, la construcción de importantes carreteras y caminos secundarios, a pesar de que aún existían zonas incomunicadas en localidades periféricas. "Estas vías 
buscaban el vínculo de las cabeceras municipales con la capital provincial, pero quedaban aisladas las áreas interiores de los municipios" (Farrill, et al., 2010).

Durante estas décadas el acceso de Las Villas y sus municipalidades a la prensa nacional estuvo favorecido por la construcción de la carretera central y las líneas de ferrocarril desde años precedentes. Periódicos como, El Heraldo de Cuba, El Diario de la Marina, Carta Semanal y La Nación, se trasladaban en tren o por automóvil por encargos y bajo la coordinación de agencias e instituciones del territorio.

\subsubsection{Coyuntura política}

La dimensión política es una de las mediaciones de mayor peso en la conformación de un sistema social y comunicativo determinado. La producción simbólica pública en ámbitos regionales y locales, además de ser reflejo de lo espontáneo y lo popular, a su vez, es resultado de lo que las estructuras de poder imponen o hacen emerger ${ }^{5}$. Para entender estos procesos en Las Villas durante las décadas de 1940 y 1950, es necesario remitirnos a lo que los historiadores nos han aportado sobre el tema desde discursos que privilegian el perfil político e ideológico.

La instalación norteamericana en la Isla desde 1902 y su afianzamiento a mediados del siglo XX dan cuenta de una etapa marcada por el control sobre las decisiones políticas a escala nacional, regional y con consecuencia en lo local. Las divisiones ideológicas surgidas desde mediados de los años treinta ${ }^{6}$ e impactaron en Las Villas, lo que hizo posible la circulación de posturas e inclinaciones diversas, que repercutieron en el espectro massmediático y en las prácticas culturales de entonces.

Es necesario señalar que las estructuras políticas del nivel nacional, regional y local fueron expresión de discursos engañosos y manipuladores. La corrupción se hizo notar en no pocas empresas, donde mediaban intereses políticos norteamericanos. Las persecuciones, los desalojos de campesinos y los fraudes de los sectores de poder para asumir cargos públicos, unido a las evidentes desigualdades sociales, las carencias y el descontrol casi total de los recursos naturales, fueron fenómenos que hicieron posible el surgimiento de ideas que a mediados de siglo se expandieron por todo el territorio nacional como expresión de rebeldía y patriotismo.

Para este tipo de análisis, es necesario indagar sobre los movimientos revolucionarios ocurridos en Las Villas y acerca de cómo la prensa, la radio, las prácticas culturales en espacios públicos y las organizaciones de sociabilidad se convierten en fieles defensoras de las nuevas ideas circulantes?

Al tratarse de movimientos de rebeldía

6 Las inclinaciones por la política del dictador Fulgencio Batista y la que surgía como respaldo a Ramón Grau san Martín, quien lideraba el entonces Partido Revolucionario Cubano (Auténtico).

7 Aunque no debe obviarse la estructuración de un sistema de comunicación nacional que fue reflejo de una sociedad contaminada por todo tipo de influencias norteamericanas. 
Es válido aclarar, que estos procesos no se dieron en todos los lugares de igual forma, ni respondían a intereses similares. Sin embargo, de enmarcarnos en ámbitos locales como Cumanayagua hacia la medianía del siglo XX, puede aseverarse una producción simbólica pública / massmediática que proclamaba un cambio del sistema político y social imperante.

Azucareros, tabacaleros, cafetaleros, ferroviarios, portuarios, transportistas, curtidores, obreros del comercio y de la construcción de diversas localidades de Las Villas participaban en las manifestaciones públicas, inspirados en ideas independentistas heredadas desde la colonia.

En 1940 los campesinos villareños celebraron su primer congreso territorial, y fundaron la Federación Campesina de Las Villas. Sus primeras demandas fueron mejorar los precios, condenar los abusos de los terratenientes y la Guardia Rural, así como aplicar una ley de reforma agraria. Hubo pronunciamientos concretos contra los desalojos ocurridos en Camajuaní, Sagua, Placetas, Vueltas, Santo Domingo y Manicaragua (Farrill, et al., 2010).

Los años presidenciales siguientes, de 1948 a 1952, estuvieron correspondidos también por auténticos y republicanos. Aunque se destacó la división producida por los primeros, cuando Eduardo Chibás funda en 1948 el Partido del Pueblo Cubano (Ortodoxo). "Durante estos años las acciones políticas ocurridas en la provincia de Santa Clara influyeron en todo el panorama cubano. Los sucesos nacionales, regionales y locales interactuaron constantemente" (Farrill, et al., 2010).

Luego de 1953 las acciones contra la tiranía batistiana ${ }^{8}$ en Las Villas se consolidaron y en ellas se incrementó el número de jóvenes. Este suceso dio lugar a huelgas, manifestaciones y entierros simbólicos. Fueron Santa Clara, Remedios y Sagua La Grande los escenarios de mayores revueltas. Se promovieron paros en las empresas y fábricas locales, unido a la concentración en espacios públicos. A propósito de las convocatorias de Batista a elecciones por el intento de legitimar su lugar en el poder en 1954, "Actos públicos, telegramas a órganos de prensa, personalidades nacionales y autoridades en general, declaraciones y marchas ocurrieron en toda la provincia" (Farrill, et al., 2010).

Asimismo, en las luchas revolucionarias de Las Villas se destacaron: el Partido Movimiento de la Nación, las Brigadas Juveniles-de formación militar, el Movimiento Revolucionario 26 de Julio, el Bloque Estudiantil Villareño-integrado por jóvenes universitarios residentes en Santa Clara, el Movimiento Sagua La Grande, el Partido y la Juventud Ortodoxa, el Directorio Revolucionario y el Partido Socialista Popular, el cual "promovía la oposición a través de la movilización popular, sobre todo en el seno del proletariado" (Farrill, et al., 2010).

En la década de 1950 la agitación popular y las protestas en espacios públicos e instituciones locales iban en ascenso, el movimiento revolucionario crecía y los sabotajes constituyeron prácticas muy comunes en Santa Clara y en otros ayuntamientos y locali-

Contra las políticas del dictador Fulgencio Batista 
dades de Las Villas. Connotación revolucionaria tuvo también el levantamiento armado en Cienfuegos el 5 de septiembre de 1956.

Fue en el año 1958 cuando el movimiento revolucionario de Las Villas se había consolidado, a pesar de los reveses propios de la contienda y la pérdida numerosa de hombres en los enfrentamientos y otros perseguidos y asesinados. Importancia tuvo para las causas revolucionarias de Las Villas luego de 1958, el Movimiento 26 de Julio, las columnas Antonio Maceo y Ciro Redondo, destacándose importantes acciones en zonas urbanas y montañosas de Las Villas.

Los medios y demás prácticas de comunicación pública se hicieron eco de los sucesos que acontecieron durante estas décadas, como resultado de la coyuntura política nacional, regional y local. Para consumar esta investigación, debe pensarse también en la incidencia de la Constitución de $1940^{9}$

Para análisis posteriores ha de examinarse en profundidad cómo la mediación política admite visualizar las agendas que a partir de la Constitución de 1940 se sostuvieron en relación con el interés regional y local, la representación de ese capital regional y de la estructura social en el poder, cargos políticos a quienes respondían.

\subsubsection{La cultura popular y la religiosidad}

Si bien, estamos en presencia de un complejo proceso de configuración social en los niveles nacional y regional, dado por la presencia norteamericana, cuyos patrones distaban de los valores tradicionales, en el caso de los ámbitos locales, se vislumbraba un espectro sociocultural más genuino y autóctono. Recuérdense las prácticas culturales que acontecieron en municipios, barrios y sectores rurales y semi-rurales, los jolgorios, las retretas, las parrandas, los guateques campesinos y las serenatas.

Una mediación importante fue la incidencia de la migración europea y asiática en estos aconteceres. Los clubes, casinos, sociedades, liceos, las instituciones religiosas y otras tendencias asociacionistas o místicas, dieron cauce a la celebración de ritos, procesiones, conmemoraciones, festejos populares y otras modalidades de comunicación pública local. Asimismo, las relaciones comerciales y la migración interna favorecieron diálogos entre la periferia y los centros urbanos más próximos y desarrollados, lo que hizo posible la expansión de formas simbólicas de todo tipo, tradiciones populares y costumbres.

Fue la religión católica la de mayor arraigo en las municipalidades y comunidades de Las Villas, a causa de la herencia hispana establecida en la Isla y en cada una de sus regiones desde siglos pretéritos. Por ende, múltiples ceremonias y procesiones religiosas tipificaron el espectro sociocultural regional y local.

\footnotetext{
$9 \quad$ El artículo 47 reflejaba: "La cultura, en todas sus manifestaciones, constituye un interés primordial del Estado, son libres la investigación científica, la expresión artística y la publicación de sus resultados, así como la enseñanza, sin perjuicio, en cuanto a ésta, de la inspección y reglamentación que al Estado corresponda y que la Ley establezca"
} 


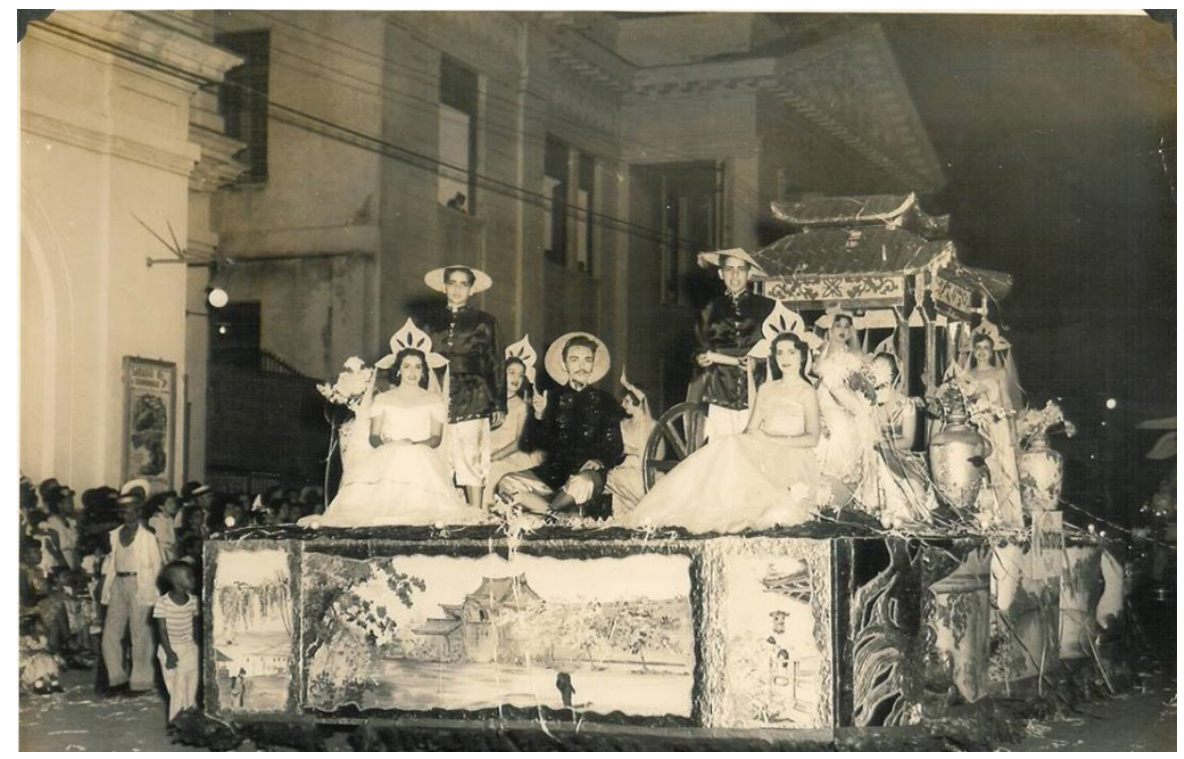

Imagen 2. Carnaval de Cienfuegos del año $1953^{10}$

\subsubsection{Incidencia de la a enseñanza pública}

Es necesario entender cómo incidió la educación en el alcance de la comunicación pública, en cuanto a producción y recepción de información. Durante la primera mitad de la pasada centuria la enseñanza pública y privada en Las Villas, si bien marcada por la desigualdad y la discriminación, cuyos niveles de desarrollo diferían del muy alto nivel de analfabetismo existente; concediéndose privilegios a los centros urbanos más cosmopolitas; también en contextos locales como Manicaragua, Cumanayagua y Cruces, con la participación de las sociedades, los clubes y las iglesias católicas y protestantes de estos contextos se promovieron prácticas educativas influenciadas por los cánones cristianos que reportaron beneficios al movimiento intelectual de entonces.

Se trata de una mediación que admite múltiples interpretaciones, a saber: la incidencia en la formación de comunicadores, en el desarrollo sociocultural local y en cuanto al nivel o alcance de los procesos de recepción y participación social.

La mayoría de los periodistas locales"1 que se destacaron en las décadas en que se enmarca el presente estudio fueron formados precisamente en las escuelas públicas que

10 Fuente: Las fotos recopiladas fueron aportadas por familias de las localidades a los estudiantes de Comunicación Social de 3er año, (curso 2014-2015), como parte de las investigaciones desarrolladas desde la asignatura Comunicación y Sociedad. Nótese la influencia norteamericana en las prácticas culturales de entonces. Se trata de un fenómeno que adquirió mayor visibilidad en la década del cincuenta, a causa de la consolidación del sistema capitalista, que se supeditaba al Gobierno Norteamericano bajo la presidencia del dictador Fulgencio Batista.

1 Debe reconocerse que por estos años el ejercicio periodístico en las localidades era realizado fundamentalmente por los intelectuales, escritores, maestros, médicos, abogados y otros profesionales de la clase media y alta, que se inclinaban por el ejercicio de la comunicación pública en la prensa periódica. No fueron los sectores pobres quienes 
auspiciaban los centros católicos. A su vez, hacia mediados del siglo ya se vislumbraba la presencia de públicos lectores, pertenecientes a las clases media y alta, capaces de interesarse por las noticias nacionales, de la provincia y en los acontecimientos locales, "no puede soslayarse la estructuración que alcanza el sistema de educación pública de la Isla ya en el siglo XX, si bien insuficiente con un gremio muy vacacionado y un encargo muy claro" (Mena, 2014, p. 61).

Notable incidencia tuvo en este sentido la Constitución de $1940^{12}$, lo que trajo consigo el surgimiento de nuevos centros de enseñanza pública en ámbitos de menor envergadura.

\subsubsection{Crecimiento poblacional}

Hacia las décadas de 1940 y 1950, debe saberse la influencia que tuvo el componente demográfico desde años precedentes en Las Villas. Recuérdense rasgos como: "aumento de la población, zonas densamente pobladas, mayor número de población rural, ligera superioridad de la población femenina, existencia mayoritaria de la población blanca y falta de trabajo para más de la mitad de la población potencialmente activa" (Farrill, D.; Yedra, B. E Venegas, 2010, pp. 145-242).

Este aumento poblacional es atribuible al proceso recuperativo posbélico, a los nacimientos naturales, y de algún modo, al mejoramiento de las condiciones de vida luego de la primera ocupación militar, a pesar de las crisis y la inestabilidad social.

El componente demográfico se reflejó en los censos de estos años, al destacarse que la población de las regiones centrales era mayoritariamente blanca. Constituía aproximadamente el setenta por ciento de la población total. El resto representaba la población negra y mestiza, los cuales se dedicaban a trabajar esencialmente en los centros urbanos, actividades domésticas, el trabajo en los puertos, la construcción y otras labores que no exigían de preparación ni escolaridad.

La situación demográfica se mantuvo relativamente similar en las entonces regiones y municipios de Las Villas. "Remedios y Sagua tuvieron otras características, sufrieron de estatismo demográfico, sobre todo la última, con un movimiento de migración interna que reforzó los vínculos regionales" (Farrill, D; Yedra, B E Venegas, 2010, pp. 145-242).

En consulta realizada a los censos de Cienfuegos de los años 1941 y 1953, en comparación con el de 1931, se percibe un incremento demográfico significativo. Tendencia

se favorecieron de la educación, excepto casos aislados con el patrocinio de organizaciones de caridad y beneficencia que surgieron en Santa Clara, Cienfuegos y Sancti Spíritus.

12 El artículo. 51 declaraba lo siguiente: "La enseñanza pública se constituirá en forma orgánica de modo que exista una adecuada articulación y continuidad entre todos sus grados, incluyendo el superior. El sistema oficial proveerá al estímulo y desarrollo vocacionales, atendiendo a la multiplicidad de las profesiones y teniendo en cuenta las necesidades culturales y prácticas de la nación. Toda enseñanza, pública o privada, estará inspirada en un espíritu de cubanidad y de solidaridad humana, tendiendo a formar en la conciencia de los educandos el amor a la patria, a sus instituciones democráticas y a todos los que por una y otras lucharon" 
similar se divisa en Sagua La Grande, Santa Clara, Sancti Spíritus y Remedios. Obsérvese en la tabla 2.

Tabla 2. Datos de los censos de Cienfuegos (1931, 1943 y 1953) $)^{13}$

\begin{tabular}{|c|c|c|}
\hline \multicolumn{3}{|c|}{ Cienfuegos } \\
\hline Año & Región & Municipio \\
\hline 1931 & 189613 & 87669 \\
\hline 1943 & 203623 & 94810 \\
\hline 1953 & 218724 & 99530 \\
\hline
\end{tabular}

Fuente: elaboración propia

En 1943 la densidad media de Cienfuegos fue de 28, $12 \mathrm{Km}^{2}$. La extensión territorial, por su parte, tenía aproximadamente unos $7.238 \mathrm{Km}^{2}$. En 1953, 55,1\% de la población radicaba en el sector urbano, mientras que 28,8\% en el espacio rural, con 1.000 habitantes.

Estas mediaciones tuvieron significación especial en el desarrollo de la comunicación pública y de sus producciones simbólicas en las décadas examinadas. Sin embargo, entender las singularidades de cada espacio local y visualizar la trilogía sistema de comunicación pública regional-local/producción simbólica/mediaciones requiere de exámenes más profundos que permitan entender, desde la perspectiva hermenéutica, cómo estamos en presencia de procesos de interdependencia entre SS y SC.

\section{Conclusiones}

El período republicano y con puntualidad, los años próximos a la Constitución de 1940 desencadenaron al nivel social transformaciones importantes en el orden de los derechos civiles en Cuba, y la participación activa de sectores sociales hasta esa fecha preteridos de la escena pública. Aun cuando estos cambios no revirtieron las deformaciones sociales que se asentaban en un modelo neocolonial impuesto desde la complicidad entre ejercicios de gobiernos burgueses aupados y legitimados por el imperialismo norteamericano, sin dudas, se favorecieron en regiones como la central la emergencia de sectores comerciales con presencia española e inmigrante, y una vida pública diversa y singular en muchos casos respecto a lo que ocurría en el resto de la Isla.

Recuperar con cientificidad y rigor de la mano de un corpus teórico-conceptual multi y pluridisciplinar, la complejidad de la producción simbólica de la región central del país, y caracterizarla tomando como referente las diversas mediaciones sociales intervinientes (económicas, políticas, culturales-institucionales), no solo ha de restituir una cartografía más exhaustiva de ese mundo de interacciones, mestizajes y creaciones socioculturales,

13 La región Cienfuegos incluía sus territorios y localidades hacia el interior, mientras que la denominación de municipio se limitaba al espacio urbano y sus barrios más próximos. 
sino hacerlo trascender hacia el presente como lo que es, un componente de articulación decisivo en la socialidad e identidad que nos distingue.

Todo ello, en correspondencia con el énfasis que se les otorga hoy a los estudios y prácticas para el desarrollo, que han de generar enfoques cada vez más holísticos, participativos, así como de políticas (culturales, educativas) y programas de transformación social (empoderamiento) que tomen en cuenta la evolución de los aconteceres, las matrices culturales que objetivan la actualidad social y la singularidad socio-histórica y simbólica de cada territorio.

Sobresale el valor epistemológico de un itinerario de análisis que, aunque se valoriza justamente por su transdisciplinariedad, coloca su punto de miras en la estructura de saberes de la comunicación como área científica de enlace con la historia, la sociología y la antropología cultural.

Las mediaciones examinadas constituyen adaptaciones que se derivan de los préstamos de la Teoría de la mediación social (1977 y 2008) y de la Teoría social de la comunicación de Manuel Martín Serrano (1986). Referencias obligadas también constituyen los aportes de otros autores, a saber: Enrique Sánchez Ruiz (1991), John B. Thompson (1993), Jesús Martín Barbero (1989, 2001 y 2010) y Hernán Venegas Delgado (2007).

Con el estudio se pretende dar solución a una de las problemáticas por las cuales transita la construcción epistémica de la comunicación en el país, otorgando valía a la producción historiográfica de la comunicación en escenarios regionales y locales, espacios que han sido poco visualizados por la academia, a saber, provincias, municipios y comunidades.

Las mediaciones en los fenómenos comunicativos y socioculturales acontecidos en épocas pasadas, incluyendo en la Contemporaneidad, admiten estudios comunicológicos apoyados en perspectivas teórico-metodológicas pluridisciplinares.

Se requiere de fundamentos teórico-metodológicos que valgan de material de consulta para otros estudiosos cubanos, con acento en la producción simbólica pública en contextos regionales y locales y desde la perspectiva hermenéutica (crítica-interpretativa), así como en la planeación y gestión de programas de desarrollo endógeno (cultural, de entretenimiento, de empleo del tiempo libre) más allá de su evidente compromiso con el rescate y el enriquecimiento del acervo identitario del país.

Se trata de una agenda de indagación (la producción simbólica pública regional-local), que si bien ha gozado de suficiente estatuto de legitimación en nuestro campo de estudio en Iberoamérica, aún se percibe la desatención de enfoques discursivos sobre prácticas y procesos no precisamente massmediáticos, que requieren de pesquisas sustentadas en las perspectivas hermenéutica, dialéctica y crítica. De esta forma, es posible arribar a peroraciones mucho más responsables en la producción historiográfica de la comunicación, máxime cuando se trata de una ciencia (la comunicación) que se encuentra en plena adolescencia y que demanda de un ensanchamiento desde diversos campos, disciplinas y puntos de vista. 


\section{Referencias bibliográficas}

Balcells, J. (2000). La investigación social. Introducción a los métodos y las técnicas. Universidad de Barcelona. Escuela Superior de Relaciones Públicas: FUERP.

Blumer, H. (1969). Symbolic interactionism: Perspective and method, Nueva Jersey: Prentice Hall.

Bourdieu, P. (1987). Capital simbólico y clases sociales. L'Arc, 72, 13-19. |Traducción de E. Tenti publicada por el Departamento de Sociología-UBA, 1987].

Brea, José L. (2009). Transformaciones de las prácticas artísticas en la era del capitalismo cultural electrónico. Revista Telos, 56 Segunda Época. Recuperada el 23 de enero de 2015. Disponible en: http://telos. fundaciontelefonica.com/telos/img/logo.gif

Cornejo Valle, Mónica. (2003). La producción simbólica del espacio urbano en Noblejas (Toledo). Inx: Las culturas de la ciudad, 1. Zainak. Cuadernos de Antropología-Etnografía (23). Eusko Ikaskuntza, Donostia-San Sebastián, pp. 431-450.

Díaz de Salas Sergio Alfaro, Mendoza Martínez Víctor Manuel1, Porras Morales Cecilia Margarita. Disponible en www.razonypalabra.org.mx Fecha de consulta: 17 de febrero de 2014.

Farrill, D, A O; Yedra, B, E; Venegas, H. (2010). Villa Clara neocolonial. Síntesis histórica provincial de Villa Clara. La Habana: Ed. Historia.

Fernández, E E Ferrán, Y. (2015). La historiografía de la comunicación en Cuba: enclave curricularizante. Memorias del VIII Encuentro Internacional de Investigadores y Estudiosos de la Información y la Comunicación-ICOM. La Habana: FCOM \& ULEPIC. Recuperado de: http://www.icomcuba.com

Fernández, A, E E Salazar, S. (2014). Historia y comunicación social: Lecturas complementarias. Volumen I, La Habana, Ed. Félix Varela.

Gracia, J. (2012). Historia de la comunicación: perspectivas metodológicas y teórico-historiográficas desde la historia cultural. Historia Contemporánea, 45. Recuperada el 6 de octubre de 2016. Disponible en: http:// www.ehu.eus/ojs/index.php/HC/article/view/7498/6678

García, L, J. (2004). La regulación de la prensa en Cuba: referentes morales y deontológicos. Tesis de Doctorado en Ciencias de la Comunicación, La Habana: FCOM-UH.

Granados, Mogrovejo, A. (2003). Procesos comunicacionales, sociedad local y desarrollo. Esfera pública local. Lima-Perú: Documento en soporte digital.

ICOM. (2013). Historia, información y comunicación, Comisión 4. Recuperada el 6 de octubre de 2016. Disponible en: http://icomcuba2013.com/2013/1 1/28/comisin-4-historia-informacin-y comunicación

Martín, Barbero, J. (1989). Comunicación y cultura: unas relaciones complejas. Telos, 19, 21 - 26.

Martín, Barbero, J. (2001). Deconstrucción la crítica: Nuevos itinerarios de la investigación. Comunicación: campo y objeto de estudio. Perspectivas reflexivas latinoamericanas. Jalisco: Instituto Tecnológico y de Estudios Superiores de Occidente (ITESO).

Martín, Barbero, J. (2010). Comunicación, espacio público y ciudadanía. Folios. Edición especial. Facultad de Comunicaciones. Universidad de Antioquia.

Martín, Serrano. M. (1986). La producción social de la comunicación. Madrid: Ed. Alianza S.A.

Mena, Méndez, D. (2014). La comunicación pública de carácter local en las décadas de 1940 y 1950.

Cumanayagua como caso de estudio. Tesis de maestría en Ciencias de la Comunicación. La Habana: Facultad de Comunicación-Universidad de La Habana. 
Nápoles, Rodríguez, E. (2007). Participación de poder local en Cuba: Un estudio de caso. (p.40). Tesis en opción al título académico de Master en Ciencias de la Comunicación. La Habana: FCOM-UH.

Rausell, P., y Carrasco, S. (2002). Cultura y producción simbólica en la Comunidad Valenciana. Un análisis sectorial e implicaciones territoriales, Arxius de Ciències Socials, 7, 249-273.

Román, Portas, M. (2000). Aspectos metodológicos de la historia de la comunicación. Ámbitos. 5. $2^{\circ}$ Semestre: 119-128.

Sandoval, C. (2002). Investigación cualitativa. Especialización en Teoría, Método. Bogotá-Colombia: Instituto Colombiano para el Fomento de la Educación Superior, ICFES.

Sánchez, Ruiz, E. (1991). Apuntes sobre una metodología histórico-estructural con énfasis en el análisis de los medios de difusión, (p. 21). Comunicación y Sociedad, 10 11.

Thompson, J. (1993). Ideología y cultura moderna. México: Editorial Universidad Autónoma Metropolitana Unidad Xochimilco.

Trujillo, J E Velazco, A. (2007). Enfoques más recientes en la investigación cubana en comunicación. Aproximaciones a la obra de Manuel Martín Serrano. Mediaciones Sociales. Revista de Ciencias Sociales y de la Comunicación, 1, segundo semestre: 93-112.

Trujillo, Janny A. (2008). Historia y comunicación social: apuntes para un diálogo inconcluso. Un acercamiento al campo de estudios históricos en comunicación. Tesis presentada en opción al título de master en Ciencias de la Comunicación. La Habana: FCOM-UH. 